\title{
Profiling service failure and customer online complaint motives in the case of single failure and double deviation.
}

\begin{abstract}
This study compares the profile of service failure in single-failure and double-deviation situations differentiates the complaint motives in both. It content-analyzed online customer complaints in two popular Malaysian foodservice chains. The first part discusses the four main service failure categories: (a) product related, (b) people related, (c) process related, and (d) physical-evidence related. The second section compares the six different types of complaint motives in single-failure and double-deviation situations. The results revealed that one case of double deviation occurred in every six cases of service failure. In addition, service failure profile and the complaint motive profile in single failures and double deviations were found to be similar. Given the findings, several important recommendations for academicians and industry practitioners were made.
\end{abstract}

Keyword: Service failure; Double deviation; Content analysis; Online complaint; Complaint motive. 